Disclosure of Interests: Ana Belén Azuaga-Piñango: None declared, Beatriz Frade-Sosa: None declared, Roberto Gumucio: None declared, Katherine Cajiao: None declared, Andrea Cuervo: None declared, Raquel Celis: None declared, Jose A. Gómez-Puerta Speakers bureau: Abbvie, BMS, GSK, Lilly, Pfizer, Roche, Raimón Sanmartí Speakers bureau: Abbvie, Eli Lilly, BMS, Roche and Pfizer, Juan de Dios Cañete: None declared, Julio Ramirez: None declared

DOI: 10.1136/annrheumdis-2020-eular.5562

\section{FRI0054 CHANGES IN DEPRESSIVE SYMPTOMS IN RHEUMATOID ARTHRITIS (RA) PATIENTS DURING TOCILIZUMAB (TCZ) THERAPY: THE GERMAN NONINTERVENTIONAL ARATA STUDY}

F. Behrens ${ }^{1}$, G. R. Burmester ${ }^{2}$, M. Feuchtenberger ${ }^{3}$, H. Kellner ${ }^{4}$,

C. Kühne ${ }^{5}$, A. Liebhaber ${ }^{6}$, M. Sieburg ${ }^{7}$, S. Wassenberg ${ }^{8}$, C. Luig $^{9}$, M. W. Hofmann ${ }^{10}$, C. Amberger ${ }^{11} .{ }^{1}$ Goethe University, Frankfurt, Germany; ${ }^{2}$ Charité-Universitätsmedizin, Berlin, Germany; ${ }^{3}$ Rheumatologie/Klinische Immunologie, Kreiskliniken Altötting-Burghausen, Burghausen, Germany; ${ }^{4}$ Schwerpunktpraxis für Rheumatologie und Gastroenterologie, Munich, Germany; ${ }^{5}$ Rheumatologische Praxis, Haldensleben, Germany; ${ }^{6}$ InternistischRheumatologische Arztpraxis, Halle, Germany; ${ }^{7}$ Rheumatologie Magdeburg, Magdeburg, Germany; ${ }^{8}$ Rheumazentrum Ratingen, Ratingen, Germany; ${ }^{9}$ Roche Pharma AG, Grenzach-Wyhlen, Germany; ${ }^{10}$ Chugai Pharma Germany GmbH, Frankfurt, Germany; ${ }^{11}$ Rheumatologische Gemeinschaftspraxis, Bad Neuenahr, Germany

Background: Depression is a common comorbidity in patients with RA and influences perception of disease activity and quality of life. We have previously reported that mean depression scores improved during TCZ therapy in conjunction with reductions in disease activity. ${ }^{1}$

Objectives: To evaluate individual changes in depressive symptoms over 52 weeks in RA patients initiating treatment with TCZ.

Methods: We analyzed data from a large German multicenter observational study of patients with active RA who initiated TCZ therapy during routine clinical care (ML29087 ARATA study; NCT02251860). The Beck Depression Inventory-II (BDI-II), a self-report questionnaire for depression screening that has been validated in RA, was used to assess symptoms of depression. Patients were classified by baseline BDI-II scores into depression categories of no (BDI-II<14), mild (BDI-II 14-19), moderate (BDI-II 20-28), and severe depression (BDI-II 229$).{ }^{2}$ Individual changes in BDI-II scores between baseline and week 52 were assessed. Erythrocyte sedimentation rate was used as the acute phase reactant in Disease Activity Score-28 joints (DAS28) assessments.

Results: Of 1155 patients enrolled from 108 clinical centers in Germany between May 2014 and July 2018, 474 completed the BDI-II at baseline (BDI-II cohort); baseline characteristics were similar to those of patients who did not complete the BDI-II. Approximately half of patients in the BDI-II cohort had BDI-II scores indicating no depression (248; $52.3 \%$ ); the remaining patients had mild (87; $18.4 \%)$, moderate $(84 ; 17.7 \%)$, or severe $(55 ; 11.6 \%)$ depression. The mean (SD) baseline characteristics of the BDI-II cohort were 55.5 (12.5) yrs of age, $75.7 \%$ female, 10.6 (9.2) yrs RA duration, 4.9 (1.2) DAS28, and 24.3 (10.2) Clinical Disease Activity Index (CDAI). Baseline DAS28 and CDAI scores were similar among different depression subgroups, but patients with severe depression were more likely to be female ( $87.3 \%$ vs $70.6 \%$ for no depression) and had higher levels of anxiety, suicidal ideation, fatigue, pain, and sleep disturbance than patients with no or milder depression.

A total of 229 of the 474 patients $(48.3 \%)$ in the BDI-II cohort completed the BDI-II at both baseline and week 52 . At 52 weeks, the depression category of approximately half of patients with depressive symptoms at baseline changed to a lower level or no depression (Figure 1). Moderate to large improvements in BDI-II from baseline (>10 points) were reported by $33.3 \%$ to $38.5 \%$ of patients with baseline depressive symptoms (Figure 2).

Conclusion: At 52 weeks after initiating TCZ, the depressive disease burden was reduced. Future analyses with a representative patient cohort will be aimed at exploring whether improvements in depression occur independent of reductions in disease activity.

References:

[1] Behrens F et al. Arthritis Rheumatol 2019;71(suppl 10):abstr1414.

[2] Smarr KL, Keefer AL. Arthritis Care Res 2011;63(S11):S454-66.

Acknowledgments: This study was sponsored by Chugai Pharma Germany $\mathrm{GmbH}$ and Roche Pharma AG. Sharon L. Cross and Kirsten Dahm provided medical writing services supported by Chugai. Statistical analyses were provided by Roche Pharma AG.

Disclosure of Interests: Frank Behrens Grant/research support from: Pfizer, Janssen, Chugai, Celgene, Lilly and Roche, Consultant of: Pfizer, AbbVie,

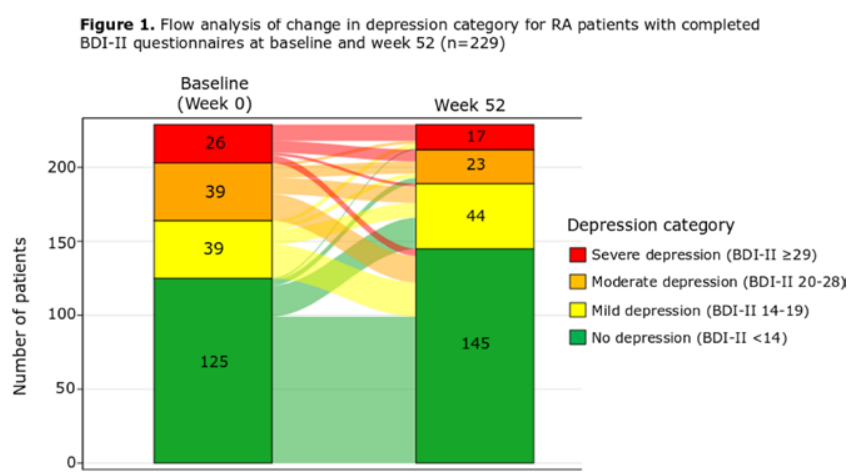

Figure 2. Improvement or deterioration of BDI-II scores over 52 weeks by BDI-II subgroup at baseline

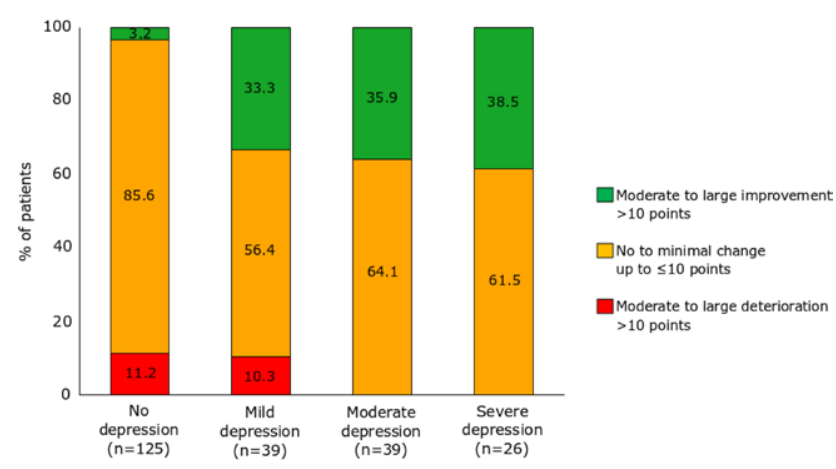

Sanofi, Lilly, Novartis, Genzyme, Boehringer, Janssen, MSD, Celgene, Roche and Chugai, Gerd Rüdiger Burmester Consultant of: AbbVie Inc, Eli Lilly, Gilead, Janssen, Merck, Roche, Pfizer, and UCB Pharma, Speakers bureau: AbbVie Inc, Eli Lilly, Gilead, Janssen, Merck, Roche, Pfizer, and UCB Pharma, Martin Feuchtenberger Consultant of: Abbvie, BMS, Chugai, Sanofi, Speakers bureau: Abbvie, BMS, Celgene, Chugai, Jansen-Cilag, Lilly, Pfizer, Roche, Sanofi, UCB Herbert Kellner: None declared, Cornelia Kühne Grant/research support from: Novartis, Amgen, Roche/Chugai, Pfizer, Celgene, AbbVie, Sanofi, Anke Liebhaber: None declared, Maren Sieburg: None declared, Siegfried Wassenberg: None declared, Christina Luig Employee of: Roche Pharma AG, Michael W. Hofmann Employee of: Chugai Pharma Germany GmbH, Christopher Amberger Grant/research support from: Chugai Pharma Germany $\mathrm{GmbH}$, Consultant of: Chugai Pharma Germany GmbH

DOI: 10.1136/annrheumdis-2020-eular.4535

\section{FRI0055 PREVALENCE OF CLINICALLY LATENT TUBERCULOSIS IN RHEUMATOID ARTHRITIS - A RETROSPECTIVE CLINICOPATHOLOGIC STUDY OF 161 AUTOPSY PATIENTS}

M. Bély ${ }^{1}$, Á. Apáthy ${ }^{2} .{ }^{1}$ Hospital of the Order of the Brothers of Saint John of God, Department of Pathology, Budapest, Hungary; ${ }^{2}$ St. Margaret Clinic, Department of Rheumatology, Budapest, Hungary

Background: The risk of tuberculosis (TB) is higher in rheumatoid arthritis (RA) than in the general population.

Objectives: The aim of this study was to determine the prevalence and histological characteristics of post-primary inactive or active TB in RA, to appraise the involvement of different organs, and to statistically assess the relationship between inactive and active TB in RA.

Methods: At the National Institute of Rheumatology 9475 patients died between 1969 and 1992; among them 161 with RA and all of them were autopsied.

RA was confirmed clinically according to the criteria of the ARA.

TB was detected at autopsy and specified histologically, retrospectively reviewing all available clinical and pathological reports.

Demographics of different patient cohorts were compared with the Student t-probe. The relationship between inactive TB and active TB with miliary dissemination was analyzed with $x^{2}$-test.

Results: Post-primary TB was associated with RA in 21 (13.04\%) of 161 patients. Post-primary TB was localized to the lung. Twelve (57.14\%) of 21 TB were histologically only fibrous, pigmented (antracothic) tuberculotic scars (fTB), and $\mathbf{9}$ $(42.86 \%)$ of 21 revealed a fibrocaseous tubercle (fcTB). One of 12 fTB and 5 of 9 